\title{
Correction to: A randomised controlled demonstration trial of multifaceted nutritional intervention and or probiotics: the healthy mums and babies (HUMBA) trial
}

Karaponi Okesene-Gafa, ${ }^{1,2}$, Minglan Li ${ }^{1}$, Rennae S. Taylor ${ }^{1}$, John M. D. Thompson ${ }^{1}$, Caroline A. Crowther ${ }^{3}$, Christopher J. D. McKinlay ${ }^{3,4}$ and Lesley M. E. McCowan ${ }^{1,2^{*}}$

\section{Correction}

In our 'Primary Outcomes' we made a typographical error [1]; the mean weekly weight gain should read $>0.27 \mathrm{~kg}$ instead of $>0.22 \mathrm{~kg}$. The 'Primary Outcomes' should read as follows:

\section{Primary outcomes}

The primary maternal outcome is the proportion of women with excessive GWG, defined as mean weekly weight gain $>0.27 \mathrm{~kg}$ between recruitment and 36 weeks (or weight at the closest gestation to 36 weeks' if 36 week weight is unavailable) [15].

The primary infant outcome is infant birthweight.

\begin{abstract}
Author details
${ }^{1}$ Department of Obstetrics and Gynaecology, Faculty of Medical and Health Science, The University of Auckland, Auckland, New Zealand. ${ }^{2}$ South Auckland Clinical School, Faculty of Medical and Health Science, The University of Auckland, Auckland, New Zealand. ${ }^{3}$ The Liggins Institute, The University of Auckland, Auckland, New Zealand. ${ }^{4}$ Department of Paediatrics: Child and Youth Health, Faculty of Medical and Health Sciences, The

University of Auckland, Auckland, New Zealand.
\end{abstract}

Received: 30 April 2018 Accepted: 30 April 2018

Published online: 04 May 2018

\section{Reference}

1. Okesene-Gafa K, Li M, Taylor RS, Thompson JMD, Crowther CA, McKinlay CJD, McCowan LME. A randomised controlled demonstration trial of multifaceted nutritional intervention and or probiotics: the healthy mums and babies (HUMBA) trial. BMC Pregnancy Childbirth. 2016;16:373. https://doi.org/10.1186/ s12884-016-1149-8.

\footnotetext{
* Correspondence: I.mccowan@auckland.ac.nz

'Department of Obstetrics and Gynaecology, Faculty of Medical and Health Science, The University of Auckland, Auckland, New Zealand

${ }^{2}$ South Auckland Clinical School, Faculty of Medical and Health Science, The

University of Auckland, Auckland, New Zealand

Full list of author information is available at the end of the article
}

(c) The Author(s). 2018 Open Access This article is distributed under the terms of the Creative Commons Attribution 4.0 International License (http://creativecommons.org/licenses/by/4.0/), which permits unrestricted use, distribution, and reproduction in any medium, provided you give appropriate credit to the original author(s) and the source, provide a link to the Creative Commons license, and indicate if changes were made. The Creative Commons Public Domain Dedication waiver (http://creativecommons.org/publicdomain/zero/1.0/) applies to the data made available in this article, unless otherwise stated. 